\title{
Epicardial microwave ablation on the beating heart for atrial fibrillation: The dependency of lesion depth on cardiac output
}

\author{
Spencer J. Melby, MD, Andreas Zierer, MD, Scott P. Kaiser, BS, Richard B. Schuessler, PhD, and Ralph J. Damiano, Jr, MD
}

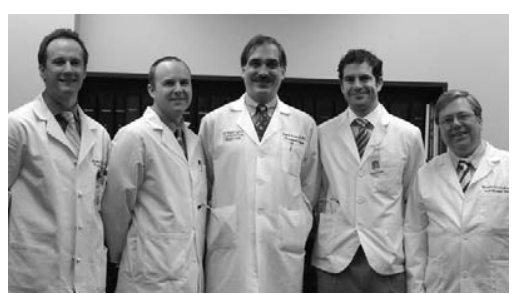

Drs Zierer, Melby, Damiano Jr, Kaiser, and Schuessler

See related editorial on page 224.

From the Division of Cardiothoracic Surgery, Department of Surgery, Washington University School of Medicine, BarnesJewish Hospital, St Louis, Mo.

The research was supported in part by $\mathrm{Na}$ tional Institutes of Health grants 5R01 HL32257, F32 HL078136-01, and R44 HL67535, and a grant to Dr. Damiano from Guidant Corporation (Santa Clara, Calif).

Received for publication Nov 18, 2005; accepted for publication Feb 6, 2006

Address for reprints: Ralph J. Damiano Jr, MD, Chief, Cardiac Surgery, Washington University School of Medicine, 660 S. Euclid Ave, Box 8234, St Louis, MO 63110 (E-mail: damianor@wustl.edu).

J Thorac Cardiovasc Surg 2006;132:355-60

$0022-5223 / \$ 32.00$

Copyright (C) 2006 by The American Association for Thoracic Surgery

doi:10.1016/j.jtcvs.2006.02.008
Background: Microwave energy is commonly used on the beating heart to create lesions for the surgical treatment of atrial fibrillation. However, lesion transmurality is likely to depend on several factors including tissue thickness and blood flow. This study was designed to determine the effect of cavitary blood flow on transmurality of acute atrial lesions with the FLEX 10 (Guidant Corporation, Santa Clara, Calif) microwave device.

Methods: Six pigs underwent median sternotomy and were placed on cardiopulmonary bypass. Microwave lesions on the atrium were performed for 60 seconds at 65 Watts at 4 different levels of cardiac output by varying cardiopulmonary bypass flow rates. Cardiac output was measured with a pulmonary artery flow probe. Four additional lesions on 2 animals were done for 120 seconds at 65 Watts with 0.0 to $0.5 \mathrm{~L} / \mathrm{min}$ cardiac output. The animals were sacrificed, and tissue was stained with 2,3,5-triphenyltetrazolium chloride and sectioned at 5-mm intervals. Lesion depth and width were determined from photomicrographs.

Results: Sixty-second lesions were transmural in $90 \%, 65 \%, 54 \%$, and $46 \%$ of atrial sections at cardiac output of 0.0 to $0.5 \mathrm{~L} / \mathrm{min}, 0.6$ to $1.9 \mathrm{~L} / \mathrm{min}, 2.0$ to $3.9 \mathrm{~L} / \mathrm{min}$, and $4.0 \mathrm{~L} / \mathrm{min}$ or greater, respectively $(P<.001)$. When ablations were performed for 120 seconds with a cardiac output of 0.0 to $0.5 \mathrm{~L} / \mathrm{min}, 100 \%$ of lesions were transmural. Lesion width was also related to cardiac output, with the widest lesions produced when cardiac output was 0.0 to $0.5 \mathrm{~L} / \mathrm{min}$.

Conclusions: Acute microwave ablation lesion depth and width are strongly dependent on the magnitude of cardiac output. Transmural lesions can be reliably produced on the porcine heart only while on cardiopulmonary bypass.

A trial fibrillation (AF) is the most common sustained arrhythmia, occurring in approximately $1 \%$ of the general population and in more than $10 \%$ of patients aged more than 80 years. ${ }^{1,2}$ The gold standard for the surgical treatment of AF, the Cox-Maze procedure, has a cure rate of more than $90 \%$ in our experience. ${ }^{3}$ However, the operation is technically challenging, requiring the creation of a complex set of incisions and reconstruction of the atria. To simplify the surgical treatment of AF, groups have attempted to use various different energy sources to replace the surgical lesions of the Cox-Maze procedure. Cryoablation, radiofrequency energy (both unipolar and bipolar), ultrasound, laser, and microwave energy have all been used to create ablation lines on the atrium. ${ }^{4-11}$ Early results of these new energy sources have been encouraging, but long-term results are still lacking. Although microwave energy has been used extensively for the treatment of $\mathrm{AF}$, there have been few studies performed to elucidate the optimum conditions for creating transmural lesions.

Microwave energy creates heat within tissue by inducing oscillation of dielectric molecules, primarily water in living tissue. ${ }^{12}$ The depth of the lesion created by the 


\author{
Abbreviations and Acronyms \\ $\mathrm{AF}=$ atrial fibrillation \\ $\mathrm{CO}=$ cardiac output \\ $\mathrm{CPB}=$ cardiopulmonary bypass \\ $\mathrm{TCC}=2,3,5$-triphenyl-tetrazolium chloride
}

microwave device depends on the power, duration, and type of antennae. ${ }^{13}$ Microwave energy can create tissue temperatures greater than $50^{\circ} \mathrm{C}$ but less than $100^{\circ} \mathrm{C}$, which allows for deep penetration without cavitation. It also results in even heating of tissue, which reduces the risk of tissue charring and possible thromboembolism. ${ }^{14,15}$

Microwave energy is currently being used clinically to create lesions for the surgical treatment of AF. Although microwave energy was initially used on the arrested heart during concomitant valve or coronary surgery, ${ }^{5,7,8}$ several groups are currently investigating the use of microwave for pulmonary vein isolation without the use of cardiopulmonary bypass $(\mathrm{CPB})$ on the beating heart. Results of these single-center experiences show a cure rate for AF of $68 \%$ to $85 \%$ at short-term follow-up up to 1 year. ${ }^{16,17}$ However, clinical experiences using this energy source were done without well-designed experimental studies defining the dose-response curve, and therefore without knowledge of ablation times or power needed to consistently reach transmurality on the beating heart.

A recent study from our laboratory on both the arrested and beating heart elucidated the dose-response curve of the microwave FLEX-10 device (Guidant Corporation, Santa Clara, Calif). This energy source consisted of a $26-\mathrm{mm}$ antenna that is encased in a flexible $53.5-\mathrm{cm}$ Teflon sheath (Figure 1). The antenna is adjustable within the sheath and can produce ablation lines $2 \mathrm{~cm}$ in length per application with a maximum ablation segment length of $20 \mathrm{~cm}(10 \times 2$ $\mathrm{cm}$ segments). In this study, the device achieved transmurality in $100 \%$ of ablated atrial sections when ablation times were 90 seconds on the arrested heart. However, on the beating heart, only $20 \%$ of lesions reached transmurality, regardless of the time of ablation. ${ }^{18}$ This lack of transmurality on the beating heart was believed to be caused by the heat-sink effect of circulating blood. Without transmural lesions, conduction block is not guaranteed and maintaining the high cure rates of the Cox-Maze procedure is less likely.

Although a dose-response curve for the microwave device on the beating heart was demonstrated, previous studies have not defined whether the depth of the microwave energy penetration is dependent on the magnitude of cavitary blood flow. This study was designed to test the hypothesis that blood flow across the endocardial surface is responsible for the tissue cooling that limits lesion transmurality on the beating heart. Cardiac output (CO) was used as an estimate of cavitary blood flow.

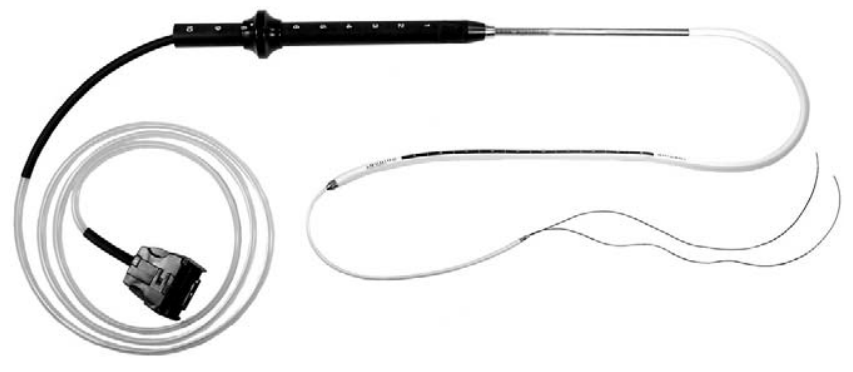

Figure 1. FLEX 10 microwave device, Guidant Corporation (Santa Clara, Calif).

\section{Materials and Methods Experimental Protocol}

Six domestic pigs weighing 50 to $70 \mathrm{~kg}$ were used in this study. All animals received humane care in compliance with the Guide for the Care and Use of Laboratory Animals (National Academy Press, Washington, DC). After overnight fasting, each animal was premedicated, intubated, anesthetized, and monitored continuously throughout the procedure.

Four separate lesions, done at $\mathrm{CO}$ of baseline (prebypass), 2.0 to $3.9 \mathrm{~L} / \mathrm{min}, 0.6$ to $1.9 \mathrm{~L} / \mathrm{min}$, or 0.0 to $0.5 \mathrm{~L} / \mathrm{min}$, were randomly assigned to positions on each atrium. These randomized lesions were performed for 60 seconds at 65 Watts using the Guidant FLEX 10 microwave ablation device.

The heart was exposed through a median sternotomy. A myocardial temperature probe was placed into the anterior wall of the left ventricle. Myocardial temperature was maintained between $36^{\circ} \mathrm{C}$ and $38^{\circ} \mathrm{C}$. An ultrasonic flow probe $(20-\mathrm{mm}$ perivascular probe, T206 Flowmeter, Transonic Systems; Ithaca, NY) was placed around the pulmonary artery for continuous measurement of $\mathrm{CO}$. Blood pressure, animal core temperature, hematocrit, and serum electrolytes were monitored throughout the procedure. Cannulae were placed in the superior and inferior vena cavae and the aorta after the administration of heparin. All lesions were applied on the epicardial surface of the atria. Before the animal was placed on $\mathrm{CPB}$, a single 2-cm lesion corresponding to a baseline $\mathrm{CO}$ (prebypass) was made on both the right and left atria free wall at a site determined by preoperative randomization. The animal was placed on $\mathrm{CPB}$, and the venous return was manipulated to obtain a $\mathrm{CO}$ of $3.0 \mathrm{~L} / \mathrm{min}$ (range 2.5-3.9 L/min). After 5 minutes of stability a second $2-\mathrm{cm}$ lesion was placed on both the right and the left atria in the preassigned randomized position. The third and fourth lesions were done similarly, with a controlled $\mathrm{CO}$ of 1.5 $\mathrm{L} / \mathrm{min}$ (range 1.3-1.6 L/min) and then on full $\mathrm{CPB}, \mathrm{CO} 0.0 \mathrm{~L} / \mathrm{min}$ (range $0.0-0.5 \mathrm{~L} / \mathrm{min}$, Figure 2 ). The first 4 animals each had a total of 8 cardiac lesions (4 lesions on each atrium).

In the final 2 animals, additional lesions of a longer duration (120 seconds) were created while the animal was on full CPB (CO 0.0-0.5 L/min). By using 2 consecutive segments on the FLEX 10 device, 2 additional lesions (each $2 \mathrm{~cm}$ in length) were created on the left atrium. Likewise, 2 lesions (each $2 \mathrm{~cm}$ in length) were added to the right atrium. The final 2 animals each had a total of 12 cardiac lesions (6 on each atrium). 


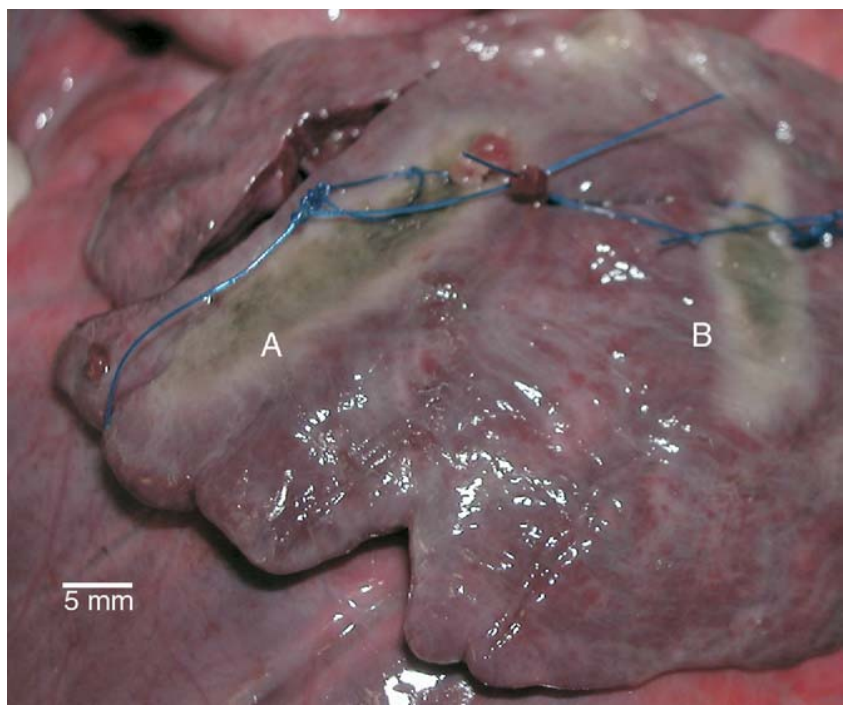

Figure 2. Left atrium postprocedure. A, Lesion done at $0.0 \mathrm{~L} / \mathrm{min}$. B, Lesion done at $5.0 \mathrm{~L} / \mathrm{min}$.

\section{Histologic Assessment}

At the end of the procedure, the animals were sacrificed and the hearts were removed en bloc. The myocardium was examined for evidence of charring, tissue disruption, and thrombus formation. The hearts were then placed in 1\% 2,3,5-triphenyl-tetrazolium chloride (TTC) solution and incubated at room temperature for 60 minutes. Each microwave lesion was sectioned at 5-mm intervals perpendicular to the long axis of the ablation line. Sections were digitally photographed with a 5-mm caliper for calibration. With commercial software (Adobe Photoshop, San Jose, Calif), lesion width, depth, and atrial tissue thickness were analyzed. The accuracy of this technique was $\pm 0.03 \mathrm{~mm} .{ }^{18}$ The lesion depth and width were measured from the unstained area to the pink halo region surrounding each lesion. A total of 193 sections were examined corresponding to an ablation time of 60 seconds, and 27 sections were examined with ablation times of 120 seconds.

\section{Statistical Analysis}

Mean width and depth were compared using the 1-way analysis of variance model. Post hoc multiple comparisons were made using the Fisher least significant difference test. Data were expressed as mean \pm standard deviation.

\section{Results}

On gross inspection, the lesions were pale and easily visible. No tissue disruption was observed. Minimal tissue charring was seen in lesions done on full $\mathrm{CPB}$, whereas no charring was seen when $\mathrm{CO}$ was greater than $0.5 \mathrm{~L} /$ minute. No thrombus formation was seen in any of the ablated atria. Atrial lesion depth was evaluated, as was atrial wall thickness in the area of ablation and the number of transmural lesion cross-sections.

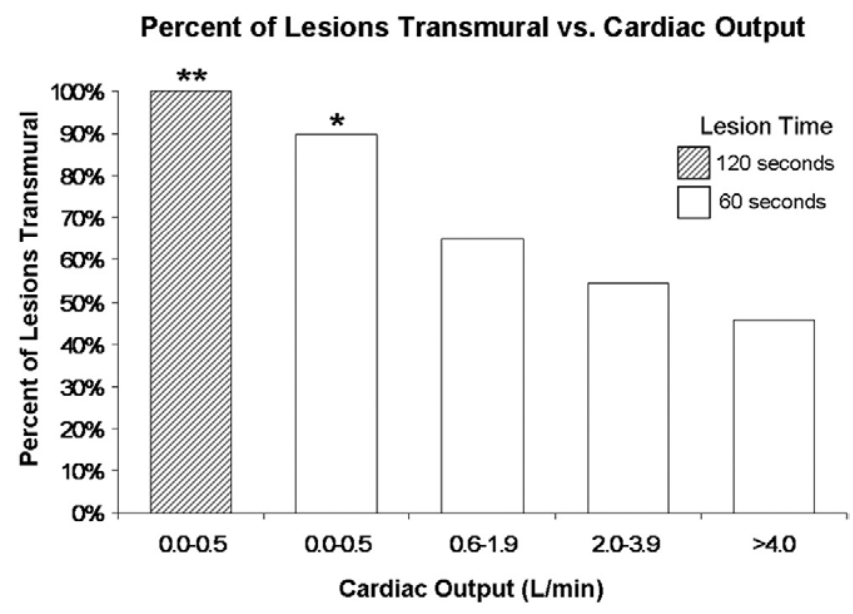

Figure 3. Lesion transmurality versus $\mathrm{CO}$. Lesions done at 120 seconds (left); lesions done at 60 seconds (right). *Statistical analysis revealed that there was a significantly higher number of lesions that were transmural in the group on full CPB $(60$-second lesions) versus the other 3 groups in which $\mathrm{CO}$ was greater than $0.5 \mathrm{~L} / \mathrm{min}(P<.01)$. **There was a trend toward significance in the number of transmural lesions in the group on full CPB for 120 seconds $(27 / 27,100 \%)$ versus the group on full CPB for 60 seconds (52/58, 90\%; $P=.092)$.

\section{Atrial Ablations}

Fifty-two of $58(90 \%)$ of atrial ablation sections done while $\mathrm{CO}$ was 0.0 to $0.5 \mathrm{~L} / \mathrm{min}$ were transmural when the ablation was applied for 60 seconds. The percentage of lesions that were transmural was inversely correlated to the level of $\mathrm{CO}$ (65\% at $\mathrm{CO}$ of $0.6-1.9 \mathrm{~L} / \mathrm{min} \mathrm{n}=40,54 \%$ at $\mathrm{CO}$ of $2.0-3.9$ $\mathrm{L} / \mathrm{min} \mathrm{n}=71$, and $46 \%$ at $\mathrm{CO}$ of $>4.0 \mathrm{~L} / \mathrm{min} \mathrm{n}=24)$. Statistical analysis revealed that there was a significantly higher number of lesions that were transmural in the group on full CPB (60-second lesions) versus the other 3 groups in which $\mathrm{CO}$ was greater than $0.5 \mathrm{~L} / \mathrm{min}(P<.01)$. When ablation duration was prolonged to 120 seconds, $100 \%$ of ablated atrial sections were transmural $(n=27$, Figure 3$)$. There was a trend toward significance in the number of transmural lesions in the group on full CPB for 120 seconds $(27 / 27,100 \%)$ versus the group on full CPB for 60 seconds (52/58, 90\%; $P=.092)$.

Lesion widths were similarly affected by $\mathrm{CO}$. When the $\mathrm{CO}$ was 0.0 to $0.5 \mathrm{~L} / \mathrm{min}$, mean lesion width was $6.0 \pm 2.8$ $\mathrm{mm}$. At $\mathrm{CO}$ of 0.6 to $1.9 \mathrm{~L} / \mathrm{min}$, the mean width decreased to $4.9 \pm 1.8 \mathrm{~mm}$, with a $\mathrm{CO}$ of 2.0 to $3.9 \mathrm{~L} / \mathrm{min}$ to $5.0 \pm 1.5$ $\mathrm{mm}$; at $\mathrm{CO}$ of greater than $4.0 \mathrm{~L} / \mathrm{min}$, the mean width decreased to only $4.4 \pm 2.0 \mathrm{~mm}$. Comparison between these groups showed that lesions were significantly wider when on full CPB versus the other 3 groups $(P<.001)$. The lesions were significantly wider when the $\mathrm{CO}$ was 0.0 to $0.5 \mathrm{~L} / \mathrm{min}$ and the lesions were done for 120 seconds: $9.7 \pm$ 


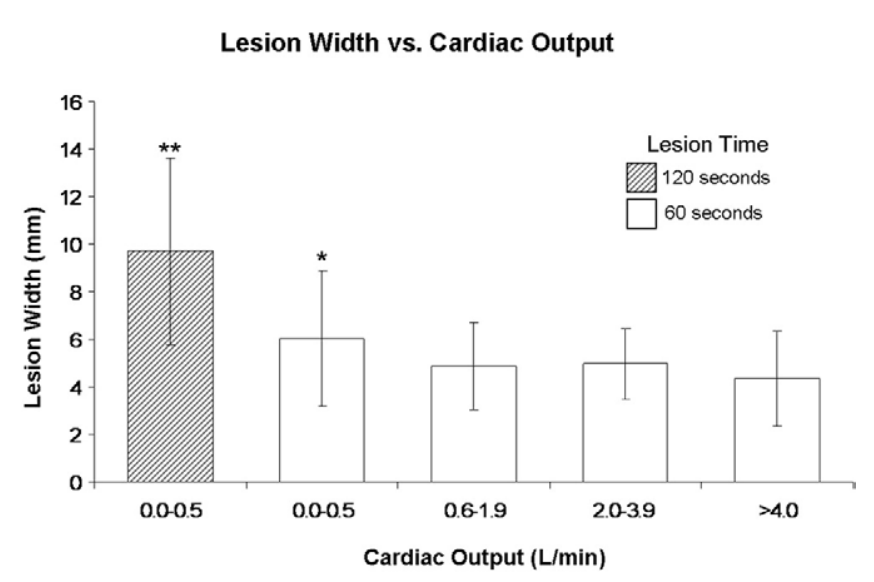

Figure 4. Lesion width versus $\mathrm{CO}$. ${ }^{*}$ Comparison showed that 60-second lesions were significantly wider when on full CPB versus the other 3 groups $(P<.001)$. **Lesions were significantly wider when the $\mathrm{CO}$ was 0.0 to $0.5 \mathrm{~L} / \mathrm{min}$ and the lesions were done for 120 seconds: $9.7 \pm 3.9 \mathrm{~mm}(P<.001$ when compared with 60 -second lesions at same $(\mathrm{O})$.

$3.9 \mathrm{~mm}(P<.001$ when compared with 60 -second lesions at same CO; Figure 4).

\section{Atrial Thickness}

Atrial wall thickness at each ablation site was measured to determine its influence on the results. The total mean atrial tissue thickness for all lesions created was $2.62 \pm 1.31 \mathrm{~mm}$ (range 0.4-6.9 mm). The mean atrial wall thicknesses of 60 -second lesions created at each $\mathrm{CO}$ were $2.7 \pm 1.4 \mathrm{~mm}$ (CO 0.0-0.5 L/min), $2.4 \pm 1.2 \mathrm{~mm}(\mathrm{CO} 0.6-1.9 \mathrm{~L} / \mathrm{min})$, $2.6 \pm 1.4 \mathrm{~mm}(\mathrm{CO} 2.0-3.9 \mathrm{~L} / \mathrm{min})$, and $2.0 \pm 0.8 \mathrm{~mm}(\mathrm{CO}>$ $4.0 \mathrm{~L} / \mathrm{min})$. The mean atrial wall thickness at the site of the 120 -second lesions ( $\mathrm{CO}$ of $0.0-0.5 \mathrm{~L} / \mathrm{min})$ was $3.4 \pm 1.5$ $\mathrm{mm}$. The thickness of the atrial wall for the 120-second lesions was significantly greater than in all other groups $(P<.02$ compared with each group). The atrium was thinnest at the site of ablations created prebypass $(>4.0$ $\mathrm{L} / \mathrm{min}$ ); it was statistically less than the mean atrial wall thickness of lesions created with $\mathrm{CO}$ of 0.0 to $0.5 \mathrm{~L} / \mathrm{min}$ $(P=.04)$ and with $\mathrm{CO}$ of 2.0 to $3.9 \mathrm{~L} / \mathrm{min}(P=.05)$.

\section{Comment}

Microwave energy has been widely used for the surgical treatment of AF, despite the lack of laboratory studies describing the specific parameters required to achieve transmurality in the clinical setting. ${ }^{5,19,20}$ Although good clinical results have been reported using this energy on both the arrested heart and the beating heart, ${ }^{21,22}$ the clinical experience has not been based on published dose-response curves for this technology on living myocardial tissue.

Recent work from our laboratory suggested that microwave ablation is not capable of consistently creating acute transmural lesions on the beating heart. ${ }^{18}$ This has been hypothesized to be the result of the heat-sink phenomenon of circulating cavitary blood flow cooling the endocardial surface. This study was designed to answer this hypothesis and determine the relationship between cavitary flow and lesion depth.

This acute study demonstrated that the FLEX 10 device was capable of producing transmural atrial lesions while on CPB if cavitary flow is reduced. Ninety percent of atrial lesions created on the heart were transmural when the cavitary blood flow was minimal (on full CPB) with ablation duration of 60 seconds, and $100 \%$ of lesions were transmural when ablation times were 120 seconds. As CO and cavitary blood flow increased, the percentage of transmural lesions was reduced. This is consistent with the hypothesis that the endocardial blood reservoir acts as a heat-sink. This finding is also consistent with Gaynor and colleagues ${ }^{18}$ findings in which only $20 \%$ of microwave lesions (even at prolonged ablation times) were transmural on the beating heart, whereas $100 \%$ of lesions done for more than 90 seconds were transmural when the heart was arrested.

When the cavitary blood flow was minimal, the majority of lesions were transmural even when ablated for only 60 seconds. The lesions that did not achieve transmurality were those located over the trabeculated areas of the right atrium, which were as thick as $6.9 \mathrm{~mm}$. When the cavitary blood flow was kept at a minimum and the ablation time was increased to 120 seconds, even the thickest areas of the atrium (up to $6.0 \mathrm{~mm}$ ) achieved transmurality. The randomization of the lesions over the course of this study was performed to prevent the local variation of atrial thickness from being a factor in lesion transmurality. Although the tissue was significantly thicker for lesions done at 120 seconds on full CPB, they were still $100 \%$ transmural. Moreover, although the atrial tissue was thinnest in the prebypass lesions done at $\mathrm{CO}$ greater than $4.0 \mathrm{~L} / \mathrm{min}$, this group had the lowest percentage of transmural lesions.

The mean width of lesions increased from $4.4 \mathrm{~mm}$ to $6.0 \mathrm{~mm}$ when the $\mathrm{CO}$ was decreased from greater than $4.0 \mathrm{~L} / \mathrm{min}$ to 0.0 to $0.5 \mathrm{~L} / \mathrm{min}$. There was also a significant difference between 60-second and 120-second ablations, with lesion width increasing to approximately $1 \mathrm{~cm}$.

To avoid collateral damage the surgeon should remain cognizant that thermal spread may extend beyond the width of the device, particularly when ablation is performed over extended time while on full CPB. These lesions are wider than those reported previously in the literature when used on the beating heart, likely because the heat-sink effect of circulating blood was eliminated when on full $\mathrm{CPB}$, which allowed tissues to reach a higher temperature. ${ }^{18}$

Past experience has proven that it is difficult to achieve transmurality on the beating heart when using a unipolar 
ablation device. Unipolar radiofrequency devices have had limited success on both the beating and arrested heart in an ovine model. ${ }^{23}$ In addition to the circulating blood pool of the beating heart, epicardial fat was believed to be a contributing negative factor in the production of transmural lesions. The results with the radiofrequency device are worse in humans, with only $8 \%$ of lesions transmural in one study. ${ }^{23-25}$ The microwave device is reported to be better at overcoming the problem of creating lesions through fat; however, the cooling effect of circulating blood has remained an impediment to creating transmural lesions.

Controversy remains over the necessity of creating transmural lesions for an effective cure of AF. Because several investigators have used microwave on the beating heart for the treatment of AF with moderate to good results, it has been argued that transmurality is not necessary.,16,22,26 However, in an acute canine model, van Brakel and colleagues ${ }^{27}$ showed that complete isolation was necessary to prevent $\mathrm{AF}$ induction by triggering from an isolated area, even though incomplete isolation decreased AF duration and lengthened the AF cycle length. Because of the intrinsic properties of myocytes to conduct electrical impulses, the theoretic consequence of leaving any intact tissue is significant. Furthermore, small areas of viable tissue may contribute to sustaining arrhythmias such as atrial flutter. ${ }^{28,29}$ Experiments performed on isolated atria have shown that leaving even very small gaps in ablation lines allowed the propagation of electrical impulses. ${ }^{30-33}$ The only guarantee of complete conduction block is a fully transmural lesion. In light of this, the results of this study suggest that microwave ablation should be used with caution on the beating heart. If a surgeon chooses to use this energy source to isolate pulmonary veins, then pacing should be used to document conduction block after the procedure.

\section{Study Limitations}

The study has a number of limitations. First, the experiments were performed in an acute model. A chronic model may have yielded different results, because it is possible that there may be lesion extension with time after microwave ablation. ${ }^{34}$ However, TTC staining has been documented to be effective, reliable, and sensitive in determining the extent of necrosis after ablation. ${ }^{35}$ Our laboratory has previously used this staining method, and found that acute results with TTC staining correlated well with chronic histology. ${ }^{36,37}$

Another limitation of this study was that normal porcine hearts were used to examine the effect of microwave ablation. It is possible that the pathologic states common in AF could alter results, especially because atrial thickness and fibrosis are increased in patients with long-standing arrhythmias and valvular disease. This may make transmural ablation more difficult to achieve. However, with adequate ablation times and no circulating blood volume to disperse the heat, it should be possible to create completely acute transmural lesions on even very thick atria.

Pulmonary artery flow was used as an estimate of left and right atria cavitary blood flow, and it may not be a precisely accurate reflection of regional flows (ie, right atrial appendage). However, it is difficult, if not impossible, to measure regional flow velocity at the time of ablation, and this should serve as a rough estimate. Moreover, this study was designed principally to look at the effect of changes in cavitary blood flow on lesion depth, and there is no doubt that there was a linear relationship between cavitary atrial blood flow and CO. Finally, observer error when determining lesion depths and widths can occur. Calipers were always photographed with the tissue samples, and 2 independent observers viewed all the tissue samples in an effort to reduce this error.

\section{Conclusion}

Acute microwave ablation lesion depth and width are dependent on cavitary blood flow. The microwave device is limited by the cooling effects of the circulating blood in the atrium because it created a lower percentage of transmural atrial lesions when the cavitary blood flow was increased more than $0.5 \mathrm{~L} / \mathrm{min}$. The use of $\mathrm{CPB}$ to decrease the circulating cavitary blood volume made the device capable of consistently producing acute transmural lesions on the atria.

\section{References}

1. Wolf PA, Abbott RD, Kannel WB. Atrial fibrillation as an independent risk factor for stroke: the Framingham Study. Stroke. 1991;22:983-8.

2. Furberg CD, Psaty BM, Manolio TA, Gardin JM, Smith VE, Rautaharju PM. Prevalence of atrial fibrillation in elderly subjects (the Cardiovascular Health Study). Am J Cardiol. 1994;74:236-41.

3. Prasad SM, Maniar HS, Camillo CJ, Schuessler RB, Boineau JP, Sundt TM 3rd, et al. The Cox maze III procedure for atrial fibrillation: long-term efficacy in patients undergoing lone versus concomitant procedures. J Thorac Cardiovasc Surg. 2003;126:1822-8.

4. Damiano RJ Jr. Alternative energy sources for atrial ablation: judging the new technology. Ann Thorac Surg. 2003;75:329-30.

5. Gillinov AM, Smedira NG, Cosgrove DM 3rd. Microwave ablation of atrial fibrillation during mitral valve operations. Ann Thorac Surg. 2002;74:1259-61.

6. Knaut M, Spitzer SG, Karolyi L, Ebert HH, Richter P, Tugtekin SM, et al. Intraoperative microwave ablation for curative treatment of atrial fibrillation in open heart surgery-the MICRO-STAF and MICROPASS pilot trial. MICROwave Application in Surgical treatment of Atrial Fibrillation. MICROwave Application for the Treatment of Atrial Fibrillation in Bypass-Surgery. Thorac Cardiovasc Surg. 1999; 47(Suppl 3):379-84.

7. Venturini A, Polesel E, Cutaia V, Asta A, Mangino D, Moretti R, et al. Intraoperative microwave ablation in patients undergoing valvular surgery: midterm results. Heart Surg Forum. 2003;6:409-11.

8. Knaut M, Tugtekin SM, Spitzer S, Gulielmos V. Combined atrial fibrillation and mitral valve surgery using microwave technology. Semin Thorac Cardiovasc Surg. 2002;14:226-31.

9. Mokadam NA, McCarthy PM, Gillinov AM, Ryan WH, Moon MR, Mack MJ, et al. A prospective multicenter trial of bipolar radiofrequency ablation for atrial fibrillation: early results. Ann Thorac Surg. 2005;78:1665-70. 
10. Banerjee A, Singh S, Tempe DK. Intraoperative endocardial ablation of chronic atrial fibrillation along with mitral valve surgery using high frequency ultrasound with a ball-tipped harmonic scalpel probe. Indian Heart J. 2004;56:178-80.

11. Reddy VY, Houghtaling C, Fallon J, Fischer G, Farr N, Clarke J, et al. Use of a diode laser balloon ablation catheter to generate circumferential pulmonary venous lesions in an open-thoracotomy caprine model. Pacing Clin Electrophysiol. 2004;27:52-7.

12. Williams M. A review of the methods of atrial tissue ablation. Heart Surg Forum. 2002;1:7-8.

13. Williams MR, Knaut M, Berube D, Oz MC. Application of microwave energy in cardiac tissue ablation: from in vitro analyses to clinical use. Ann Thorac Surg. 2002;74:1500-5.

14. Gillinov AM, McCarthy PM, Marrouche N, Natale A. Contemporary surgical treatment for atrial fibrillation. Pacing Clin Electrophysiol. 2003;26(7 Pt 2):1641-4.

15. Williams MR, Argenziano M, Oz MC. Microwave ablation for surgical treatment of atrial fibrillation. Semin Thorac Cardiovasc Surg. 2002;14:232-7.

16. Molloy TA. Midterm clinical experience with microwave surgical ablation of atrial fibrillation. Ann Thorac Surg. 2005;79:2115.

17. Salenger R, Lahey SJ, Saltman AE. The completely endoscopic treatment of atrial fibrillation: report on the first 14 patients with early results. Heart Surg Forum. 2004;7:E555-8.

18. Gaynor SL, Byrd GD, Diodato MD, Ishii Y, Lee AM, Prasad SM, et al. Microwave ablation for atrial fibrillation: dose-response curves in the cardioplegia-arrested and beating heart. Ann Thorac Surg. 2006;81:72.

19. Maessen JG, Nijs JF, Smeets JL, Vainer J, Mochtar B. Beating-heart surgical treatment of atrial fibrillation with microwave ablation. Ann Thorac Surg. 2002;74:S1307-11.

20. Schuetz A, Schulze CJ, Sarvanakis KK, Mair H, Plazer H, Kilger E, et al. Surgical treatment of permanent atrial fibrillation using microwave energy ablation: a prospective randomized clinical trial. Eur J Cardiothorac Surg. 2003;24:475-80; discussion 480.

21. Saltman AE, Rosenthal LS, Francalancia NA, Lahey SJ. A completely endoscopic approach to microwave ablation for atrial fibrillation. Heart Surg Forum. 2003;6:E38-E41.

22. Knaut M, Tugtekin SM, Jung F, Matschke K. Microwave ablation for the surgical treatment of permanent atrial fibrillation-a single centre experience. Eur J Cardiothorac Surg. 2004;26:742-6.

23. Hoenicke EM SRJ, Patel H, Prophet GA, Damiano RJ Jr. Initial experience with epicardial radiofrequency ablation catheter in an ovine model: moving towards an endoscopic Maze procedure. Surg Forum. 2000;51:79-82.

24. Thomas SP, Guy DJ, Boyd AC, Eipper VE, Ross DL, Chard RB. Comparison of epicardial and endocardial linear ablation using handheld probes. Ann Thorac Surg. 2003;75:543-8.
25. Santiago T, Melo J, Gouveia RH, Neves J, Abecasis M, Adragao P, et al. Epicardial radiofrequency applications: in vitro and in vivo studies on human atrial myocardium. Eur J Cardiothorac Surg. 2003;24:481-6; discussion 486.

26. Wisser W, Khazen C, Deviatko E, Stix G, Binder T, Seitelberger R, et al. Microwave and radiofrequency ablation yield similar success rates for treatment of chronic atrial fibrillation. Eur J Cardiothorac Surg. 2004; 25:1011.

27. van Brakel TJ, Bolotin G, Nifong LW, Dekker AL, Allessie MA, Chitwood WR Jr, et al. Robot-assisted epicardial ablation of the pulmonary veins: is a completed isolation necessary? Eur Heart J. 2005;26:1321.

28. Shah D, Haissaguerre M, Jais P, Takahashi A, Hocini M, Clementy J. High-density mapping of activation through an incomplete isthmus ablation line. Circulation. 1999;99:211.

29. Scharf C, Oral H, Chugh A, Hall B, Good E, Cheung P, et al. Acute effects of left atrial radiofrequency ablation on atrial fibrillation. $J$ Cardiovasc Electrophysiol. 2004;15:515-21.

30. Melby SJ LA, Schuessler RB, Damiano RJ. The effect of residual gaps in ablation lines for the treatment of atrial fibrillation. Heart Rhythm. 2005;2:S15.

31. Thomas SP, Wallace EM, Ross DL. The effect of a residual isthmus of surviving tissue on conduction after linear ablation in atrial myocardium. J Interv Card Electrophysiol. 2000;4:273-81.

32. Ishii $Y$, Nitta $T$, Sakamoto $S$, Tanaka S, Asano G. Incisional atrial reentrant tachycardia: experimental study on the conduction property through the isthmus. J Thorac Cardiovasc Surg. 2003;126:254-62.

33. Mitchell MA, McRury ID, Everett TH, Li H, Mangrum JM, Haines DE. Morphological and physiological characteristics of discontinuous linear atrial ablations during atrial pacing and atrial fibrillation. J Cardiovasc Electrophysiol. 1999;10:378-86.

34. van Brakel TJ, Bolotin G, Salleng KJ, Nifong LW, Allessie MA, Chitwood WR Jr, et al. Evaluation of epicardial microwave ablation lesions: histology versus electrophysiology. Ann Thorac Surg. 2004; 78:1397-402; discussion 1397-402.

35. Adegboyega PA, Adesokan A, Haque AK, Boor PJ. Sensitivity and specificity of triphenyl tetrazolium chloride in the gross diagnosis of acute myocardial infarcts. Arch Pathol Lab Med. 1997;121: 1063-8.

36. Prasad SM, Maniar HS, Moustakidis P, Schuessler RB, Damiano RJ Jr. Epicardial ablation on the beating heart: progress towards an off-pump maze procedure. Heart Surg Forum. 2002;5:100-4.

37. Prasad SM, Maniar HS, Schuessler RB, Damiano RJ Jr. Chronic transmural atrial ablation by using bipolar radiofrequency energy on the beating heart. J Thorac Cardiovasc Surg. 2002;124:708-13. 